\title{
Acute adrenal insufficiency as a manifestation of the anticardiolipin syndrome?
}

\author{
SIMON CARETTE AND FRANÇOIS JOBIN \\ From the Department of Medicine, Laval University, Quebec City, Canada
}

SUMmARY A 34 year old man with a past history of deep vein thrombosis, positive lupus్ serology, and high titres of anticardiolipin antibodies developed acute adrenal insufficiency? Association of anticardiolipin antibodies with adrenal insufficiency has not been previously reported.

Key words: anticardiolipin antibodies, systemic lupus erythematosus.

Anticardiolipin antibodies have been associated with recurrent venous and arterial thrombosis, thrombocytopenia, fetal losses, and neurological disease. ${ }^{1}$ We report a patient with 'atypical lupus' and raised anticardiolipin antibody titres who developed acute adrenal insufficiency.

\section{Case report}

A 34 year old white man was admitted to hospital in January 1984 with a 24 hour history of cramp-like lower abdominal pain and fever. He had returned a few days earlier from a two week cruise in the Caribbean. At the age of $\mathbf{1 7}$ he had suffered from a deep femoral vein thrombosis confirmed by venography. A routine blood test when he was 19 had shown the presence of antinuclear antibodies in a low titre.

The abdominal pain had started a few hours after playing squash. He did not complain of nausea, vomiting, or diarrhoea. Physical examination on admission was unremarkable except for a temperature of $38^{\circ} \mathrm{C}$, skin hyperpigmentation, attributed to his recent trip, and right lower abdominal tenderness without guarding. Laboratory findings showed haemoglobin $146 \mathrm{~g} /$, white blood cell count

Accepted for publication 23 July 1988 .

Correspondence to Dr Simon Carette, Le Centre Hospitalier de l'Université Laval, 2705 boulevarde Laurier, Sainte-Foy, Quebec G1V 4G2, Canada.
$10 \cdot 1 \times 10^{9} / 1$ with a normal differential, platelets $208 \times 10^{9} / 1$, and Westergren sedimentation rate of $53 \mathrm{~mm} / \mathrm{h}$. Blood urea and electrolytes were normal Blood, stool, and urine cultures were negative. The patient subjectively improved and was discharge $\Phi$ nine days later without a specific diagnosis.

He was readmitted to hospital a week later feeling extremely weak and still complaining of abdominal pain. He was dehydrated and had lost $4.5 \mathrm{~kg}$. Hi temperature was $37.5^{\circ} \mathrm{C}$ and blood pressure $70 / 38$ $\mathrm{mmHg}$. Laboratory investigation showed haemoglo 3 . bin $125 \mathrm{~g} / 1$, white blood cell count $1.9 \times 10^{9} / 1(67 \%$ neutrophils), and platelet count $154 \times 10^{9} / 1$. Bloo urea was $14.3 \mathrm{mmol} / \mathrm{l}$, serum potassium $6.1 \mathrm{mmol} / \mathrm{l}$ 옹 sodium $117 \mathrm{mmol} / \mathrm{l}$, and creatinine $150 \mu \mathrm{mol} / \mathrm{l}^{\mathrm{S}}$ Repeated blood, stool, and urine cultures were negative. Partial thromboplastin time was $101.5 \overline{\bar{\delta}}$ (control $33.6 \mathrm{~s}$ ), prothrombin time $13.9 \mathrm{~s}$ (contro P $11 \cdot 1 \mathrm{~s}$ ), and thrombin time $34 \mathrm{~s}$ (control $17 \mathrm{~s}$ ). The addition of normal plasma did not correct these abnormalities. Factor II was reduced to $\mathbf{0 \cdot 3 5}$. High titres of fibrin degradation products determined twice with a 12 hour interval were presenf $(>1280 \mu \mathrm{g} / \mathrm{l}$, normal $<80 \mu \mathrm{g} / 1)$. Fibrinogen waș? $3.96 \mathrm{~g} / 1$ (normal range (NR) 1.6-4.2 g/l). Antinuclear antibodies (homogeneous pattern) were. present (1/1280). Veneral Disease Research Labora $\vec{\rho}$ tory (VDRL) test and direct Coombs' test werब positive. Anti-DNA, antithyroid, anti-adrenal, and antismooth muscle antibodies were absent. Serum cortisol was $49 \cdot 7 \mathrm{nmol} / \mathrm{l}$ (NR 190-700 $\mathrm{nmol} / \mathrm{l}$ ). 
A diagnosis of primary adrenal insufficiency was made, and the patient was treated with steroids. His clinical status rapidly improved. The diagnosis was confirmed by a three day corticotrophin stimulation test, which showed decreased urinary cortisol concentration ( $\max : 88 \mathrm{nmol} / 24 \mathrm{~h}, \mathrm{NR} 200-745$ ). He has remained completely asymptomatic, treated with a maintenance dosage of cortisone acetate $37 \cdot 5$ $\mathrm{mg}$ and fludrocortisone acetate $0.05 \mathrm{mg}$ daily. Analysis of stored serum samples obtained in June 1984 (four months after his hospitalisation) showed high levels of anticardiolipin antibodies (enzyme linked immunosorbent assay (ELISA): 1.86 optical density (OD) units, normal $<0.4$ OD units ${ }^{2}$ ).

\section{Discussion}

Idiopathic or autoimmune Addison's disease accounts for more than $85 \%$ of all cases of primary adrenal insufficiency. ${ }^{3}$ Anti-adrenal antibodies are detected in two thirds of the patients, ${ }^{3}$ and other tissue autoantibodies are frequently seen. Interestingly, antinuclear antibodies are rarely present and, so far, only two cases of primary adrenal insufficiency have been reported in association with systemic lupus erythematosus. ${ }^{45}$ In both cases vasculitis restricted to the adrenal glands, and not autoimmunity, was suggested as the underlying pathophysiological mechanism.

Our patient had clinical and serological manifestations typical of those previously described in patients with anticardiolipin antibodies. ${ }^{1} \mathrm{He}$ had a history of venous thrombosis at a young age and numerous abnormalities were demonstrated in his serum (antinuclear antibodies, leucopenia, 'lupus anticoagulant', low factor II, false positive VDRL test, and positive Coombs' test). Like many patients with antibodies against cardiolipin he did not satisfy the revised criteria for a diagnosis of systemic lupus erythematosus. ${ }^{6}$

Although we cannot rule out an autoimmune aetiology to his adrenal failure, the absence of antiadrenal antibodies, the negative family history, and the fact that autoimmune adrenal insufficiency has never been reported in typical systemic lupus erythematosus militate against this hypothesis. We believe that bilateral adrenal vein thrombosis should be considered as a possible aetiology in this case in view of the underlying hypercoagulable state (anticardiolipin antibodies) and the presence of high titres of fibrin degradation products during the acute episode. The absence of septicaemia, the normal platelet count, and fibrinogen concentration argue against the suggestion that increased fibrin degradation products may be explained by disseminated intravascular coagulation.

Adrenal vein thrombosis is a rare cause of adrenal insufficiency, which has been reported mainly in necropsies. ${ }^{7}$ Diagnosis of adrenal vein thrombosis is by adrenal venogram. This was not carried out in our patient as the diagnosis was not suspected at the time.

No anticoagulant treatment or prophylaxis was prescribed for our patient, and he has remained symptom free despite the persistence of serological abnormalities.

\section{References}

1 Hughes G R V, Harris N N, Gharavi A E. The anticardiolipin syndrome. J Rheumatol 1986; 13: 486-9.

2 Hazeltine M, Rauch J, Danoff D, Esdaile J M, Tannenbaum H. Antiphospholipid antibodies in SLE: evidence of an association with Coombs' and hypocomplementemia. J Rheumatol 1988; 15: 80-6.

3 Burke W. Adrenocortical insufficiency. Clin Endocrinol Metab 1985; 14: 947-76.

4 Eichner H L, Schambelan M, Biglieri E G. Systemic lupus erythematosus with adrenal insufficiency. Am J Med 1973; 55: $700-5$.

5 Thiagarajan D, Wongsurawat N. Systemic lupus erythematosus associated with adrenal insufficiency. Journal of the Kansas Medical Society 1978; 79: 565-6.

6 Tan E M, Cohen A S, Fries J F, et al. The 1982 revised criteria for the classification of systemic lupus erythematosus. Arthritis Rheum 1982; 25: 1271-7.

7 Xarli V P, Steele A A, Davis P J, Buescher E S, Rios C N, Garcia-Bunuel R. Adrenal hemorrhage in the adult. Medicine (Baltimore) 1978; 57: 211-21. 